\section{Estimation of genetic parameters for flower anomalies in papaya}

\author{
Pedro Corrêa Damasceno Junior ${ }^{1 *}$, Telma Nair Santana Pereira ${ }^{2}$ \\ and Messias Gonzaga Pereira²
}

\begin{abstract}
Floral abnormalities in papaya cause fruit deformation and yield reduction in some periods of the year. This study aimed to evaluate 23 inbreed lines and 22 hybrids in crosses between the lines Solo and Formosa in relation to floral abnormalities, and to develop a methodology to estimate summer sterility by counting of nodes without fruits. The traits evaluated were: number of carpelloid and pentandric fruits (in March and July 2007); number of nodes without fruit and neck length (in December 2006 and April 2007); and sum of abnormalities. Hybrids presented means higher than those of the lines for all abnormalities. The capelloidy was seasonal only for lines, and the pentandry showed the lowest coefficients of determination for lines and hybrids. The number of nodes without fruit was adequate to infersummer sterility. This anomaly was the most important in the lines and hybrids.
\end{abstract}

Key words: Carica papaya, carpelloidy, pentandry, summer sterility.

\section{INTRODUCTION}

Carica papaya is a diploid species with $2 \mathrm{n}=2 \mathrm{x}=18$ chromosomes (Damasceno Junior et al. 2009a, Damasceno Junior et al. 2010). Plants from this species may segregate as female, male and hermaphrodite. The hermaphrodite type is used in the Brazilian agriculture and it shows both autogamy and allogamy; however, according to Damasceno Junior et al. (2009b), Carica papaya is predominantly autogamous. Floral abnormalities are commonly seen in hermaphrodite types (Damasceno Junior et al. 2008, Silva et al. 2007).

Papaya production is seasonal, i.e., environmental effects interfere with genetic factors and affect yield. According to Arkle Junior and Nakasone (1984), mainly the environmental conditions can induce changes in papaya hermaphrodite flowers. Flower modification and fruit production seasonality contribute to the price oscillations in the market. The result of the impact of the neck or summer sterility is the yield reduction. The so-called summer sterility refers to the suppression of ovarian development in hermaphrodite flowers, making them essentially male (Storey 1941), leading to the non-formation of fruit from the affected flowers. According to Silva et al. (2007), Damasceno Junior et al. (2008) and Arkle Junior and Nakasone (1984), summer sterility occurs in the warmer seasons of the year, and its effect on fruit harvest appear a few months later and vary according to environmental conditions, such as high temperatures, low nitrogen levels, and stress caused by water deficiency, as mentioned by Arkle Junior and Nakasone (1984).
Crop Breeding and Applied Biotechnology 18: 9-15, 2018 Brazilian Society of Plant Breeding. Printed in Brazil http://dx.doi.org/10.1590/198470332018v18n1a2 (n) 
Changes in fruit shape are rather common in papaya, caused by flower deformation such as stamen carpelloidy and pentandry. Stamen carpelloidy is the transformation of flower stamens into carpels, i.e., the stamens are completely connected to the wall of the flower ovary, and become indistinguishable from carpels in some cases. This flower anomaly can vary in degree, and therefore, since papaya flower has 10 stamens, the adhesion to the ovary wall can vary from 1 to 10 . However, in all cases, this adhesion causes fruits deformation, so they fail to meet commercial standards. Stamen carpelloidy can be triggered by environmental factors, such as high soil moisture and high relative humidity, as well as high nitrogen levels. Another flower anomaly is pentandry, which is the reduction in the number of stamens from 10 to 5 , causing deep furrows in the flower ovary wall. This anomaly results in deformed fruits that do not meet the commercial standards (Arkle Junior and Nakasone 1984).

Commercial papaya plantations are ginoic-andromonoic, i.e., female and hermaphrodite plants are grown together; the latter are mainly observed in definitive plantations, since only this sexual type can produce fruit according to commercial standards. Hermaphrodite plants are highly susceptible to the slightest environmental changes, which may make the incidence of carpelloidy, pentandry and summer sterility a serious problem for the crop, affecting yields significantly. Furthermore, hermaphroditic genotypes show different levels of floral abnormalities (Luz et al. 2015, Dantas et al. 2015, Ramos et al. 2011, Damasceno Junior et al. 2008, Silva et al. 2007). These differences allow the selection of genotypes less susceptible to flower anomalies. According to Damasceno Junior et al. (2008) and Silva et al. (2007), reduction of summer sterility is the primary objective of breeding programs, despite the complexity of the expression of this trait.

Given the problems generated by floral anomalies, summer sterility, carpelloidy, and pentandry, the aim of the current study is to assess lines and hybrids for common flower alterations in Carica papaya, and to estimate some important genetic parameters in order to understand such anomalies. The study also aims to indirectly assess summer sterility by the counting of nodes without fruits.

\section{MATERIAL AND METHODS}

\section{Experimental site}

Plants of the lines Solo and Formosa (first experiment) and hybrids (second experiment) of C. papaya, planted in mid-April 2006, were evaluated in two different seasons, in late March and early July 2007, in experimental plantations at Fazenda Macuco of the company Caliman Agrícola S/A, in Linhares (lat $19^{\circ} 06-19^{\circ} 18^{\prime} \mathrm{S}$, long $39^{\circ} 45-40^{\circ} 19^{\prime} \mathrm{W}$ ), ES.

\section{Plant material}

The first experiment involved the following lines of group Solo: Caliman M5, Triwan Et, Diva, Grampola, Sunrise Solo, Caliman GB, Caliman G, Kapoho Solo (yellow pulp), Baixinho Sta. Amália, Caliman SG, S. Mateus, Kapoho Solo (red pulp), Sunrise Solo (progeny Tainung), MamãoRoxo,and SS72/12; and the following lines of group Formosa: Costa Rica, Tailândia, Waimanalo, MamãoBené, Maradol (from Mexico), Maradol (Grande limão), Sekati, and JS12.

The second experiment evaluated $21 \mathrm{~F}_{1}$ hybrids resulting from crosses between lines of group Solo, listed in experiment 1 , with an elite tester Formosa (JS12), and hybrids resulted from crosses between lines of group Formosa (listed in experiment 1), with a Solo elite tester (SS72/12), as well as the cross Mamão roxo x SS72/12.

\section{Statistical design and experimental conditions}

The experiment consisted of randomized blocks with two replications and 10 plants per plot. Trees were arranged in double rows, spaced $3.6 \times 2.0 \times 1.8$ mapart, with microsprinkler irrigation. The soil was classified as a Red Yellow Podzolic with sandy-clay texture, subperennial forest phase/rainforest forest sub-stage, and plain to slightly wavy relief (coastal plateau). All cultural treatments were used as recommended for the crop.

\section{Analyzed variables and methodological criteria}

The current study evaluated the following traits: number of carpelloid fruits (NCF); number of pentandric fruits (NPF); neck length (NLE), in centimeters; and number of nodes without fruits (NWF). It also estimated the SUM variable, which corresponded to the sum of NCF, NPF and NWF. The NCF and the NPF referred to the production of deformed 
fruits: the carpelloid and pentandric types, respectively. The NWF and the NLE corresponded to indirect inferences about summer sterility.

The first thinning of carpelloids and pentandrics flowers and of deformed fruits was carried out in November 2006 in order to estimate the NCF and the NPF, as well as to avoid counting the same deformed fruits in both evaluation periods. Thus, deformed fruits counted in the first assessment - which was performed in March 2007 - had developed from December 2006 to March 2007. A new thinning was performed at the end of the first assessment. Therefore, the second assessment - which was carried out in July 2007 - corresponded to the deformed fruits that had developed from April to July 2007. The mean temperatures in the period from December 2006 to March 2007 and from April to July 2007 were, respectively, 25 and $22{ }^{\circ} \mathrm{C}$. These mean temperatures were statistically different by the $\mathrm{T}$ test at $5 \%$ probability. The temperature data were collected at the meteorological station installed in the experimental area.

All plants in the experiment were marked in the upper portion of the stem using a woolen yarn, in order to measure the number of nodes without fruits (NWF), and to avoid counting the same NWF in the two assessment periods. The marking was performed in four months, in two distinct periods: from August to November 2006, and from December 2006 to March 2007. The average air temperature in the period from August to November 2006 was of $21.5^{\circ} \mathrm{C}$, and in the period from December 2006 to March $2007,25^{\circ} \mathrm{C}$. These data were collected in the climatological station in the experimental area. The mean temperature was analyzed by the T test for the two by two means comparison. These means were statistically different at $5 \%$ probability. The result in both cases was the senescence and fall of male flowers, which resulted in scars (nodes without fruits) in the stem. By convention, each counted node without fruit corresponded to a non-produced fruit. The number of nodes without fruit (NWF) was counted in December 2006 and April 2007. The assessments were always performed one (1) month after the end of each marking period. Thus, there was enough time for the plants to abort the summer sterile flowers and to exhibit a node without fruit in the same region.

NLE was measured in centimeters, in the plant stem area, where no fruit production was observed, caused by the emergence of summer sterile flowers. Such measurement was only performed when the area showed at least three nodes without fruits. NLE was measured by digital images from each plant used in the experiment. A known-size scale was positioned near the neck area on the stem of the plants. After the neck length images were captured, they were analyzed using the Image software, version 1.32 (Rasband 2002). NLE was obtained in the same areas marked for analysis of the node without fruit (NWF), and analyzed at the same time.

Based on the NWF estimates, summer sterility was transformed into lost fruits in order to create the SUM variable, which corresponded to the sum of NCF, NPF, and NWF. The sum of the anomalies was obtained using the mean of the period (SUM), the highest ( $\mathrm{SUM}_{\text {major }}$ ) and lowest (SUM ${ }_{\text {minor }}$ ) values for NWF, NCF, and NPF, regardless of the period. The lowest and the highest values for NFC and NPF were obtained in March and July 2007, respectively. The lowest and the highest values for NWF were obtained in December 2006 and March 2007, respectively. The SUM variable provided information on the reduction in the marketable fruit production, which was caused by floral anomalies reported in papaya plants, namely: sex reversal (summer sterility), and pentandry and carpelloidy.

\section{Statistical analysis and genetic parameters}

The Genes software (Cruz 2001) was used for all statistical analysis of the variables NCF, NPF, NWF, SUM, and NLE. The means, based on the plot, were transformed by the expression $\sqrt{x+1}$.

Based on the estimates from the analysis of variance, the coefficient of genotypic determination $\left(H^{2}\right)$, genotypic variability $\left(\hat{\varphi}_{g}\right)$, genotypic coefficient of variation $\left(\widehat{C V}_{g}\right)$, experimental coefficient of variation $\left(\widehat{C V}_{e}\right)$, residual variance $\left(\hat{\sigma}^{2}\right)$, and the index of variation (IV) were calculated.

The Pearson's correlation analysis was performed between the variable SUM, SUM ${ }_{\text {minor }}$ and SUM major with the variables that compose it: NWF, NCP, and NPF. The objective was to determine the variable that most contributed to the reduction of the number of fruits in the crop

\section{RESULTS AND DISCUSSION}

No statistically significant difference was observed for the sources of variation versus season for NPF in the lines and 
hybrids; for NLE in the hybrids; and for NCF and NPF in the hybrids.

In general, when compared with the lines, hybrids presented the highest means for the three anomalies studied here (carpelloidy, pentandry, and summer sterility), as explained by the heterosis expression in the hybrids (Table 1). Heterosis is the manifestation of the hybrid force, which is expressed by the difference between the mean value of parents and $F_{1}$ generation, and according to Falconer and Mackay (1996), heterosis occurs when there is genetic divergence between parents and dominance effect in the expression of the trait.

The production of carpelloid (NCF) and pentandric (NPF) fruits in the lines is generally different from the production in the hybrids. Statistically speaking, the production of carpelloid and pentandric fruits in the lines (Tables 2 and 3 ) was higher from April to July 2007 (NCF and NPF evaluated in July 2007). The average air temperature in this period was lower than in the previous evaluation, being $22{ }^{\circ} \mathrm{C}$ in the period from April to July, 2007 , and $25^{\circ} \mathrm{C}$ in the period from December 2006 to March 2007.In the hybrids, this anomaly was higher all year long, regardless of the seasonal effect. In general, production of carpelloid fruit was higher than that of pentandric fruits (Table 1). However, Ramos et al. (2011) observed higher production of pentandric fruit than carpelloid fruit in a segregating papaya population obtained by backcrossing. Silva et al. (2007) also assessed a segregating papaya population and observed that some hybrids presented no deformed fruits, both in summer and winter. Craene et al. (2011) showed that MADS-box class genes

Table 1. Summary of analysis of variance (mean squares) of the combined season and genetic parameters of the traits: in March and July 2007, number of carpelloid fruits (NCF), and number of pentandric fruits (NPF), number of nodes without fruits (NWF) and neck length (NLE), in cm; and sum of NCF + NPF + NWF (SUM) in papaya inbreed lines and hybrids

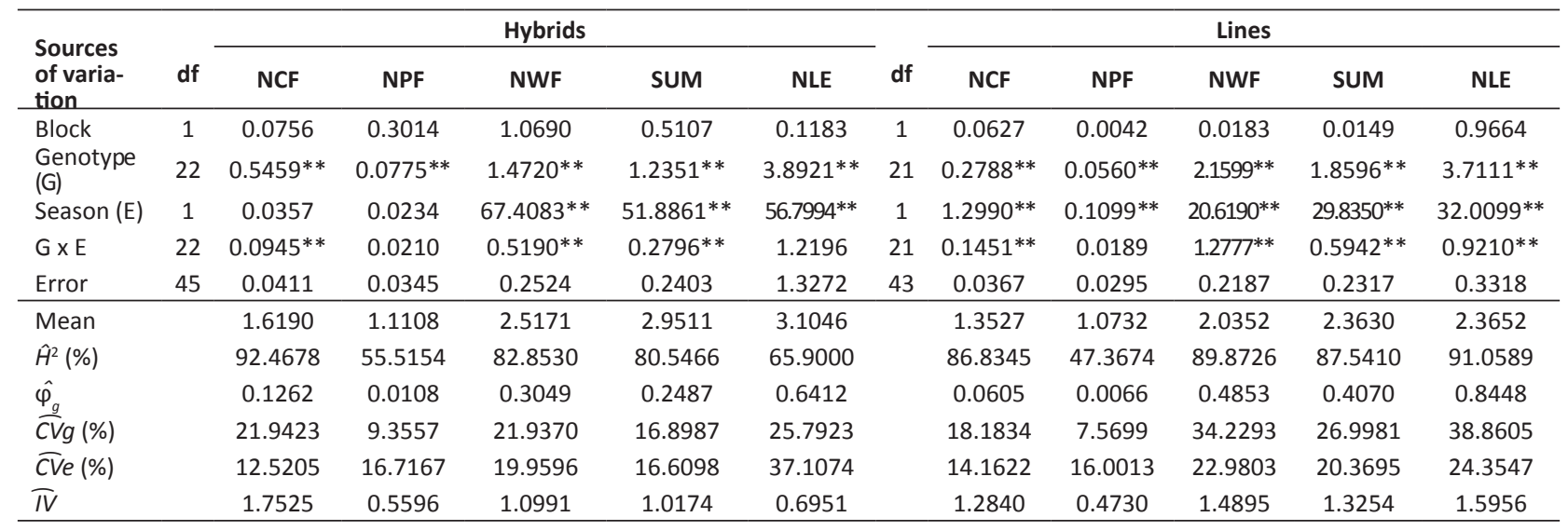

** Significantat1\% probability; $\hat{H}^{2}=$ Coefficient ofgenotypic determination in percentage; $\hat{\varphi}_{q}=$ Genotypic variability; $\widehat{C V} g=$ Coefficient ofgenetic variation; $\widehat{C V} e=$ Coefficient ofexperimental variation; $\overline{I V}=$ Variation index. Data transformed by the expression $\sqrt{X+1}$.

Table 2. Summary of analysis of variance (Meansquares) and genetic parameters of the traitsnumber ofcarpelloidfruits (NCF) evaluated in March and July 2007,number ofnodes without fruits (NWF), andneck length (NLE), in cm, evaluated in December 2006 and April 2007, and sum ofNCF + NPF + NWF with higher $\left(S_{\text {major }}\right)$ and lower values $\left(S U M_{\text {minor }}\right)$ for the occurrence of these anomalies in papaya lines

\begin{tabular}{|c|c|c|c|c|c|c|c|c|c|}
\hline \multirow{2}{*}{$\begin{array}{l}\text { Sources of } \\
\text { variation }\end{array}$} & \multirow[b]{2}{*}{ df } & \multicolumn{2}{|c|}{ NCF } & \multicolumn{2}{|c|}{ NWF } & \multicolumn{2}{|c|}{ SUM } & \multicolumn{2}{|c|}{ NLE } \\
\hline & & March & July & December & April & SUM $_{\text {minor }}$ & SUM ${ }_{\text {major }}$ & January & April \\
\hline Block & 1 & 0.12678 & 0.000004 & 0.14922 & 0.3333 & 0.4828 & 0.27303 & 0.5014 & 0.4652 \\
\hline Line & 22 & $0.11399 * *$ & $0.30983 * *$ & $1.41024 * *$ & $2.0273 * *$ & $1.1948^{* *}$ & $1.2589 * *$ & $2.9097^{* *}$ & $1.7224 * *$ \\
\hline Error & 22 & 0.02149 & 0.05066 & 0.10839 & 0.31793 & 0.1021 & 0.3380 & 0.2296 & 0.4491 \\
\hline Mean & & 1.2339 & 1.4715 & 1.5618 & 2.5086 & 1.7936 & 2.9325 & 1.7754 & 2.9551 \\
\hline$\hat{H}^{2}(\%)$ & & 81.1474 & 83.6490 & 92.3140 & 84.3175 & 91.4546 & 73.1511 & 92.1091 & 73.9259 \\
\hline$\widehat{C V} e(\%)$ & & 11.8805 & 15.2958 & 21.0799 & 22.4777 & 17.8150 & 19.8253 & 26.9891 & 22.6777 \\
\hline$\overline{I V}$ & & 1.4662 & 1.5994 & 2.4526 & 1.6395 & 2.3131 & 1.1671 & 2.4159 & 1.1906 \\
\hline
\end{tabular}

See codes in Table 1. 
Table 3. Summary of analysis of variance (Meansquares) and genetic parameters ofthetraits number of carpelloid fruits (NCF) evaluated in March and July 2007, number of nodes without fruits (NWF) evaluated in December 2006 and April 2007, and sum of NCF + $\mathrm{NPF}+\mathrm{NWF}$ with higher $\left(\mathrm{SUM}_{\text {major }}\right)$ and lower values $\left(\mathrm{SUM}_{\text {minor }}\right)$ for the occurrence of these anomalies, and neck length (NLE), in cm, in papaya hybrids

\begin{tabular}{|c|c|c|c|c|c|c|c|}
\hline \multirow[b]{2}{*}{ Sources of variation } & \multirow[b]{2}{*}{ df } & \multicolumn{2}{|c|}{ NCF } & \multicolumn{2}{|c|}{ NWF } & \multicolumn{2}{|c|}{ SUM } \\
\hline & & March & July & December & April & SUM $_{\text {minor }}$ & SUM $_{\text {maior }}$ \\
\hline Block & 1 & 0.05495 & 0.02383 & 0.15660 & 3.45183 & 0.19179 & 2.09847 \\
\hline Hybrid & 21 & $0.29744 * *$ & $0.34299 * *$ & $0.51031 * *$ & $1.48076 * *$ & $0.53345^{* *}$ & $0.98124 * *$ \\
\hline Error & 21 & 0.04265 & 0.04138 & 0.14231 & 0.2536 & 0.13887 & 0.26836 \\
\hline Mean & & 1.6391 & 1.5988 & 1.6419 & 3.3923 & 2.1832 & 3.71897 \\
\hline$\hat{H}^{2}(\%)$ & & 85.6609 & 87.9355 & 72.1130 & 82.8737 & 73.9675 & 72.6509 \\
\hline$\widehat{C V} e(\%)$ & & 12.5995 & 12.7233 & 22.9758 & 14.8450 & 17.0691 & 13.9295 \\
\hline$\pi$ & & 1.7283 & 1.9090 & 1.1371 & 1.5555 & 1.1919 & 1.1524 \\
\hline
\end{tabular}

See codes in Table 1.

participate in the transformation of stamens into carpels in Arabidopsis thaliana. Therefore, they are directly related to the development of carpelloidy in that species. Nevertheless, the genetic mechanism that induces floral abnormalities in C. papaya is still poorly understood.

Summer sterility, measured by the NWF (number of nodes without fruit) varied according to the genetic structures of genotypes, lines and hybrids, and the trait expression is higher in the warmer seasons of the year (Tables 2 and 3 , respectively). The number of nodes without fruit in papaya plants was counted in a practical way, and it allowed efficient estimation of summer sterility levels. The main advantage of such methodology is the no-need to count individual flowers in the hermaphroditic plants. Besides being extremely laborious, such counting may lead to mistaken conclusions during selection of lines, hybrids and individual genotypes with low summer sterility rates. Summer sterile and hermaphroditic flower may occur in the same flower axil. The existence of one or a few hermaphroditic flowers may be sufficient for fruit production in this axil, even with a great number of summer sterile flowers.

The coefficients of determination were relatively high for all traits, regardless of the season. However, for traits with significant effect of genotype $x$ season interaction, such as NLE, in the hybrids, and NPF, in the lines and hybrids, lower values were obtained for the parameter in question, especially the NPF, with values of 47.36 and $55.51 \%$, respectively (Table 1). Petrandry (NPF) presented low values of the index of variation (IV) in the lines and hybrids (Table 1), indicating low genetic variability of the trait. These results indicate greater difficulty in the selection of plants with reduced pentandry levels in the lines and hybrids. The same difficulty was observed for summer sterility in the hybrid, when assessing the neck length in centimeters $\left(H^{2}=65.90\right.$, Table 1$)$. In this study, the index of variation (IV) showed wide genetic variability for the NCF in the lines and hybrids (Tables 1, 2 and 3). Dantas et al. (2015) found high genetic variability for deformed fruits evaluated in papaya lines and hybrids. However, these authors did not differentiate the carpelloid from the pentandric fruits of the evaluated variable.

The coefficients of determination for NWF in the lines were of 92.31 and $84.31 \%$ in evaluations carried out in December 2006 and April 2007, respectively (Table 2). For the hybrids, the coefficients of determination for NWF were of 72.11 and 82.87 in the evaluations of December 2006 and April 2007, respectively (Table 3). Higher values for the coefficients of determination were also reported for NFC. In the lines, the coefficients of determination were of 81.14 and $83.64 \%$ in the evaluations carried out in March and July 2007, respectively (Table 2). In the hybrids, the coefficients of determination were of85.66 and 87.93, in March and July 2007, respectively (Table 3). These estimates may indicate successful selection of plants with reduced levels of summer sterility and carpelloidy.

Number of carpelloid fruit (NCF) in the lines was higher during the coldest months of the year, with higher mean in July (1.47) than in March (1.23) (Table 2). Silva et al. (2007), in a study onC. papaya, observed that for the first backcross generation $\left(\mathrm{BC}_{1}\right)$, the number of deformed flowers (carpelloid and pentandric) was higher in the cooler seasons of the year. In the hybrids, the means were of 1.63 and 1.59 (Table 3), respectively, in March and July, although, as stated above, 
no statistically significant differences were observed for this season (Table 1). Also in agreement with Damasceno Junior et al. (2008) and Silva et al. (2007), low temperatures may contribute to increased carpelloidy. Martelleto et al. (2011) carried out a study with cultivar Baixinho de Santa Amália, with manually bifurcated trunks. The authors observed little occurrence of carpelloid fruits and a large number of summer sterile flowers.

The highest incidence of summer sterility, both in the lines and hybrids, was observed in April 2007 (Tables 2 and 3 , respectively). The values for NWF and NLE always corresponded to the previous season; in other words, the nodes without fruits evaluated in April 2007 corresponded to the summer sterile flowers of the warmer seasons of the year (December 2006 to march 2007), and nodes without fruit evaluated in December 2006 corresponded to the summer sterile flowers of the cooler season of the year (August to November 2006). The higher incidence of summer sterility is related to the warmer months of the year. According to Silva et al. (2007), Damasceno Junior et al. (2008) and Storey (1941), the occurrence of summer sterility increases in the warmest months of the year.

At the time of highest incidence of summer sterility, the hybrids were more sensitive to this anomaly than the lines. The means of NWF were, respectively, 3.39 (Table 3) (real mean=11.33) and 2.50 (Table 2) (real mean=6.81), in the hybrids and lines, respectively, corresponding to a greater reduction of fruit yield per hectare for the hybrid. The means for NWF in December 2006 were very low when compared with those obtained in April 2007. As expected, NLE, which indirectly refers to the measurement of nodes without fruit, was also higher in the hybrids. NLE was not statistically different for season effect, both inthe hybrids and inthe lines (Table 1). Summer sterility can be evaluated by counting the number of NWF, as proposed and performed in this study, and indirectly inferred from the number of fruits lost from the plant, owing to summer sterility.

Correlation analysis showed that summer sterility (NWF) was the trait that most influenced SUM, SUM major and $\mathrm{SUM}_{\text {minor }}$ (Table 4). All correlations were positive and significant by the T testat $5 \%$ probability. Correlations between SUM and NWF were estimated at 0.95 and 0.92, in the lines and hybrids, respectively. Correlations between SUM minor and NWF were estimated at 0.97 and 0.78 , in the lines and hybrids, respectively. Correlation between SUM major ${ }_{\text {and }}$ NWF were estimated at 0.94 and 0.92 , in the lines and hybrids, respectively. Table 4 shows the other correlations. Consequently,summer sterility is the most influent reproductive factor in the reductionof papaya productivity. According to Almeida et al. (2003), in papaya plants grown under different irrigation levels, summer sterility was the main cause of fruit reduction, when compared withcarpelloidy and pentandry. Therefore, of the traits studied here, summer sterility must be the primary focus of breedersin the search of genotypes less sensitive to this flower alteration. According to Damasceno Junior et al. (2008) and Silva et al. (2007), mother plants without such problem can reduce summer sterility. Yamanishi et al. (2006) observed the seasonal effect on papaya fruit yield in the cultivars Tainung 01 and Sekati, which hadhigher yield in spring than in summer, when summersterility rates are higher.

The mean sum of anomalies (SUM ${ }_{\text {major }}$ ) was high in the hybrids and lines (Tables 3 and 2, respectively). Conversely, higher

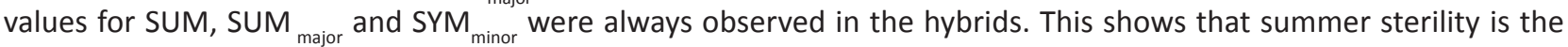
main problem in papaya crop when considering floral abnormalities. The SUM values represent an important source of information regarding the reduction of papaya yield due to flower alterations, and based on this dependent variable, the reproductive performance of each genotype can be inferred.

Considering the general means, when compared with the lines, the hybrids always presented higher values for all the traits studied (carpelloidy, pentandry, and summer sterility). This fact could be linked to expression ofheterosis

Table 4. Pearson's correlation between number of carpelloid fruits (NCF), number of pentandric fruits (NPF), number of nodes without fruits (NWF) with sum of NCF + NPF + NWF, with higher values of abnormalities (SUM major $_{\text {o }}$ ), sum with lower of abnormalities (SUM minor $_{\text {) }}$ and sum of the seasons (SUM), in papaya lines and hybrids evaluated in two seasons

\begin{tabular}{lcccccc}
\hline & \multicolumn{3}{c}{ Lines } & \multicolumn{2}{c}{ Hybrids } \\
\cline { 2 - 6 } & NCP & NPF & NWF & NCP & NPF & $0.17^{* *}$ \\
\hline SUM & $0.08^{*}$ & $0.15^{* *}$ & $0.95^{* *}$ & $0.21^{* *}$ & $0.92^{* *}$ & $0.36^{* *}$ \\
SUM $_{\text {minor }}$ & 0.03 & $0.10^{*}$ & $0.97^{* *}$ & $0.44^{* *}$ & $0.78^{* *}$ & 0.09 \\
SUM $_{\text {major }}$ & -0.01 & $0.13^{* *}$ & $0.94^{* *}$ & $0.16^{*}$ & $0.92^{* *}$ \\
\hline
\end{tabular}

*, ** Significantat $5 \%$ and $1 \%$ of probability, respectively; higher values for NFC and NPF were obtained in July 2007 ; lower values for NFC and NPF were obtained in April 2007; higher values for NWF were obtained in March 2007; lower values for NWF were obtained in December 2006. 
in the hybrid materials. In general, carpelloidfruit yield in the lines was seasonal. However, in the individual context, some hybrids also presented this seasonality forcarpelloidy. The significant effect for genotype $\mathrm{x}$ season interaction for carpelloidy in the hybrids corroborates with the aforementioned (Table 1). Luz et al. (2015) verified strong genotype $x$ time interaction for summer sterility and deformed fruits. However, these authors did not separate carpelloid frompentadric fruits. Carpelloidy in the hybrids was more pronounced than in the lines. The highest means for this anomaly were observed for the hybrids.

The counting of the number of nodes without fruit (NWF) is recommendedto measure summer sterility, since the methodology shows the number of fruits lost per genotype due to the anomaly, besides being practical. The incidence of summer sterilityis higherin the warmest months of the year. This variable influenced the reduction in papaya fruit yieldmostly due to the high positive and significant correlation with the sum of deficiencies (SUM). Therefore, the priority in papaya breeding is to reduce the level of summer sterility.

\section{REFERENCES}

Almeida FT, Marinho CS, Souza EF and Grippa S (2003) Expressão sexual do mamoeiro sob diferentes lâminas de irrigação na região norte fluminense. Revista Brasileira de Fruticultura 25: 383-385.

Arkle Junior TD and Nakasone HY (1984) Floral differentiation in the hermaphroditic papaya. Hortscience 19: 832-834.

CraeneLRD,Tréhin C, Morel P andNegrutiu I (2011) Carpeloidy in flower evolution and diversification: a comparative study in Carica papaya and Arabidopsis thaliana. Annals of Botany 107: 1453-1463.

Cruz CD (2001) Programa Genes: Aplicativo computacional em genética e estatística. UFV,Viçosa, 648p.

Damasceno Junior PC, Costa FR, Pereira TNS, Neto MF and Pereira MG (2009a) Karyotype determination in three Caricaceae especies emphasizing the cultivated form (Carica papaya L.). Caryologia 61: 10-15.

Damasceno Junior PC, Pereira TNS, Neto MF and Pereira MG (2010) Meiotic behavior of Carica papaya and Vasconcellea monoica. Caryologia 63: 229-236.

Damasceno Junior PC, Pereira TNS, Pereira MG, Silva FF, Souza M and Nicoli R (2009b) Preferential reproduction mode of hermaphrodite papaya plant. Revista Brasileira de Fruticultura 31: 182-189.

Damasceno Junior PC, Pereira TNS, Silva FF, Viana AP and Pereira MG (2008) Comportamento floral de híbridos de mamoeiro (Carica papaya L.) no final do verão e início da primavera. Revista Ceres 55: 310-316.

Dantas JLL, Lucena RS and Vilas Boas AS (2015) Avaliação agronômica de linhagens e híbridos de mamoeiro. Revista Brasileira de Fruticultura
37: $138-148$.

Falconer DS and Mackay TFC (1996) Introductionto quantitative genetics. Longman, London, 463p.

Luz LN, Pereira MG, Barros FR, Barros GB and Ferreguetti GA (2015) Novos híbridos de mamoeiro avaliados nas condições de cultivo tradicional e no semiárido brasileiro. Revista Brasileira de Fruticultura 37: 159-171.

Martelleto LAP, Ribeiro RLD, Martelleto MS, Vasconcellos MAS and Pereira MB (2011) Expressão da esterilidade feminina e da carpeloidia em mamoeiro sob diferentes ambientes de cultivo protegido. Revista Brasileira de Fruticultura 33: 1185-1193.

Ramos HCC, Pereira MG, Silva FF, Viana AP and Ferreguetti GA (2011) Seasonal and genetic influences on sex expression in a backcrossed segregating papaya population. Crop Breeding and Applied Biotechnology 11: 97-105.

Rasband W (2002) ImageJ 1.32v. National Institutes of Health, USA. Available at <http://imagej.nih.gov/ij>. Accessed on jan 15, 2002.

Silva FS, Pereira MG, Ramos HCC, Damasceno Junior PC, Pereira TNS, Viana AP, Daher RF, Ramos HCC and Ferreguetti GA (2007) Evaluation of the sexual expression in a segregating $\mathrm{BC}_{1}$ papaya population. Crop Breeding and Applied Biotechnology 7: 16-23.

Storey WB (1941) The botany and sex relationships of the papaya. In Papaya production in the Hawaiian Islands. Hawaii Agricultural Experiment Station, Hawaii, p. 5-22 (Technical Bulletin 87).

Yamanish OK, Mello RM, Martins VA, Lima LA and Fagundes GR (2006) Comportamento do mamoeiro Sekati nas condições do oeste da Bahia. Revista Brasileira de Fruticultura 28: 79-82

(c) $\mathrm{EY}$ This is an Open Access article distributed under the terms of the Creative Commons Attribution License, which permits unrestricted use, distribution, and reproduction in any medium, provided the original work is properly cited. 